\title{
A área de Ensino de Ciências e a interface com a área da Saúde ${ }^{1}$
}

\section{The area of Science teaching and its interface with Health}

Luiza Rodrigues de Oliveira ${ }^{2}$

Eu sustento que a única finalidade da Ciência está em aliviar a miséria da existência humana.

(Bertold Brecht)

\section{Resumo}

Este texto, em forma de ensaio, discute a aproximação entre a Área de Ensino de Ciências e as ciências humanas, com a finalidade de refletir acerca do surgimento de cursos com ênfase em Saúde nessa Área. Para tanto, apresenta os vários modelos de formação do conhecimento pelos quais a Área passou até chegar à interface atual com o discurso de Vygotsky. E é essa interface, ao trazer à cena o conceito de sujeito histórico social, que vem possibilitando a constituição do Ensino de Ciências a partir das afirmaçóes das ciências humanas. Uma dessas afirmaçôes apresenta o chamado Novo Conceito de Saúde que, por meio da idéia de que Saúde é a condição de acesso às práticas sociais, faz com que a Saúde deixe de ser apenas objeto das práticas tradicionais em hospitais e postos de saúde e ganhe outros lugares, um deles a escola. Este fato justifica a constituição de programas de pesquisa voltados para o estudo do Ensino de Ciências da Saúde.

Pavavras-chave: Ensino de Ciências; Ciências Humanas; Saúde; Vygotsky.

\begin{abstract}
Summary this text, in the form of testing, discusses the rapprochement between the science education area and the humanities, to reflect about the emergence of courses with emphasis on health in this area. To this end, it displays the various models of knowledge training for which the area went until you reach the current interface with Vygotsky's speech. And is this interface, bringing the concept of social history, which is allowing the formation of science education from statements of the humanities. One of these assertions presents the so-called new concept of health, through the idea that health is the condition of social practices, access causes health no longer only traditional practices object in hospitals and health posts and get other places, one school. This fact justifies the creation of search programmes focused on the study of health science education.
\end{abstract}

Keywords: science education; Humanities; health; Vygotsky.

\footnotetext{
${ }^{1}$ Palestra proferida no I Simpósio em Ensino de Ciências e Meio Ambiente do Rio de Janeiro/UniFOA/Volta Redonda/RJ/Agosto/2009.

${ }^{2}$ Doutora em Educaçáo: ênfase em Ensino de Ciências e Matemática, pela Universidade de São Paulo; Coordenadora do Mestrado Profissional em Ensino de Ciências da Saúde e do Ambiente do Centro Universitário Plínio Leite; Professora do Instituto Superior de Educaçáo do Estado do Rio de Janeiro.
} 


\section{INTRODUÇÃO}

Este texto é um ensaio sobre o tema "Ensino de Ciências da Saúde”. Para tanto, aborda o percurso da área de Ensino de Ciências com a finalidade de buscar possíveis aproximaçóes com o conceito de Saúde que expliquem a interface entre essas áreas, justificando, assim, a existência de cursos com ênfase em ensino e saúde na área de Ensino de Ciências e Matemática. Atualmente existem 06 (seis) programas que apresentam essa ênfase (UNIFOA; FIOCRUZ; UNIPLI; UFRJ; UFRGS; UNIFESP) em um total de 56 (cinqüenta e seis) programas.

A Área de Ensino de Ciências, com a finalidade de realizar pesquisas sobre a construção do conhecimento científico e desenvolver metodologias para a educação científica, existe há quase cinqüenta anos. Pode-se pensar suas origens nos grandes projetos curriculares do final dos anos cinqüenta e início dos sessenta na Europa: o PSSC em Física, o CBA em Química e o BSCS em Biologia (MOREIRA, 2008), cujo objetivo era formar cientistas. No Brasil, a área se originou, no final dos anos 60, a partir de programas stricto sensu estabelecidos na UFRGS (Mestrado em Física com uma área de concentração em Ensino de Física) e também na USP com o Mestrado em Ensino de CiênciasModalidade Física.

Do ponto de vista epistemológico, a área passou por momentos que engendram diversas abordagens para o sujeito do conhecimento, o que gerou metodologias também diferentes para a construção do conhecimento científico. Assim, a área foi transformando seu objetivo inicial - formar cientistas, passando a ter como finalidade a formação em ciências como uma das possibilidades de inclusão social.

\section{A ÁREA DE ENSINO DE CIÊNCIAS: DE POS- NER À VYGOTSKY...}

O caminho percorrido pela Área de Ensino de Ciências revela modelos acerca do processo de construção de conhecimento científico. Será possível identificar, nos modelos citados, uma determinação das ciências naturais - alvo da área de ensino de ciências, tal como vimos em seu histórico. $\mathrm{O}$ objetivo de constituir metodologias para o ensino da Física, da Química e da Biologia possibiltou que a área se aproximasse de uma abordagem positivista em Educação. Ou seja, tal como os fenômenos naturais são regidos e ordenados por leis ou tendências gerais, procedeu-se em Educação uma concepçáo do fato social - a aprendizagem científica - da mesma maneira.

Um dos modelos é o da Mudança Conceitual de Posner, que estabelece analogia entre a concepçáo kuhniana sobre o progresso da ciência e o processo de aquisição de conhecimento científico pelas pessoas. Tal modelo enfatiza a necessidade do estabelecimento da insatisfação com as concepçóes existentes, da inteligibilidade, da fertilidade e da plausibilidade (ARRUDA e VILLANI, 1994). Sendo assim, desenvolve a idéia de que um conceito é construído a partir de uma insatisfação com a concepção prévia, o que gera um desequilíbrio. As críticas indicam que esse é um modelo que não gera explicaçóes de como se constroem os processos cognitivos.

Um outro modelo é o da Teoria do Desenvolvimento de Piaget, o qual evidencia a construção da inteligência nos aspectos que favorecem a adaptação do homem à sociedade. Piaget, assim, minimiza a importância do contexto históricosocial. Para ele, a construção do conhecimento é um processo contínuo, caracterizado por diversos estágios, que definem um momento de desenvolvimento ao longo do qual a criança constrói estruturas cognitivas. A aprendizagem está centrada no sujeito do conhecimento (PIAGET, 1986).

Os dois modelos apresentados nos remetem ao sujeito cognitivo, como costumamos dizer em Psicologia, aquele responsável pela origem do conhecimento. Esse é o sujeito da Modernidade, sinônimo de indivíduo. São, portanto, apoiados por uma filosofia do sujeito que tem um caráter a-histórico. Quando falo de uma filosofia do sujeito não me refiro a nenhuma tendência/escola filosófica específica, mas à concepção que dá prevalência ao sujeito sobre o objeto no ato de construção do conhecimento.

Este contexto produziu uma pesquisa em Ensino de Ciências mais próxima do método das ciências naturais, tomando o objeto que é próprio das ciências humanas - o processo de ensino-aprendizagem - como um simples fenômeno da natureza. Assim, o lugar constituído pela área de Ensino de Ciências é aquele que o aproxima do método das ciências naturais, o que determina o entendimento da subjetividade como obstáculo ao conhecimento. É importante lembrar, também, das contribuiçôes da psicanálise fortemente discutido e apresentado pelo Prof. Villani (VILLANI e CABRAL, 2001). No início dos anos 90, a área de Ensino de Ciências inicia uma aproximação com a psicanálise. A perspectiva é a ruptura com o discurso cartesiano, apontando um sujeito, o do Desejo, para além da lógica da Razão no processo de construção do conhecimento.

Desde a Interpretação dos Sonhos (1900), a psicanálise coloca o discurso no centro das atençôes, já que é aí que o sujeito (do Inconsciente- ICS) ganha mobilidade, ou, melhor dizendo, se institui, isto é, aparece e desaparece nas armadilhas da Associaçáo Livre, a partir de deslocamentos, de condensaçóes.

Novo conceito de discurso, de subjetividade e de memória, categorias negadas pelo positivismo. O discurso 
após Freud é aquele que é fundado numa dupla voz, de enunciação e enunciado, "mostrando" um sujeito dividido pelas marcas da "memória", que não se configura por um somatório de dados, mas pela construção e reconstrução do passado, a partir de uma problemática do presente.

Numa visão mecanicista, a História, a memória, o passado aparecem como entrave, pois dificultam o uso da razão, da experimentação e da lógica. $\mathrm{O}$ passado é entendido como tendo existência "em si”, como um "arquivo morto" que deve ser ultrapassado para que o novo surja, para que não impeça o desenvolvimento no caminho da "verdade". Sendo assim, a ciência mecanicista abre mão da memória porque entende que esta carrega a verdade científica de produçóes subjetivas. Freud, porém, problematizou a memória e o esquecimento, enfatizando o dinamismo da memória, rompendo com a historiografia romântica e nos apresentando a possibilidade de "inventar", "produzir" o passado. Mas, se essa idéia nos afasta da origem de um conjunto de fatos, também não deve nos aproximar de “(...) uma absoluta arbitrariedade das construçóes a respeito do passado. Os limites da invenção do passado são dados por uma coerência que se apóia $\mathrm{m}$ vestígios, fontes, sinais e testemunhos, legitimadores dessa construção" (BUENO et al, 1993, p. 305).

Para "escutar a memória”, é preciso recusar o conceito de discurso como simples suporte para a transmissão de informações, entendendo que o enunciado está sempre atravessado pelo implícito e que é exatamente aí, entre o que se revela se escondendo, que se constitui o sujeito. O discurso é, portanto, cena enunciativa. Sendo assim, não se trata, quando da utilização da autobiografia como tipo de pesquisa, de analisar as entrevistas, reconhecendo as regularidades, mas, sobretudo, de identificar os estranhamentos ao instituído.

Ainda quanto ao método para a problematização da memória no discurso, Alberti (1991) diz:

Do ponto de vista da relação entre autor e narrador, teríamos uma identidade clara, assumida, que se manifesta no presente da enunciação: é o autor que escreve aquelas linhas; é ele que narra, no momento presente, a história. Já entre autor e personagem, o que teríamos não constitui identidade, mas, antes, uma relação de semelhança, uma vez que o sujeito do enunciado (personagem) apesar e inseparável da pessoa que produz a narração (o autornarrador está falando dele mesmo), dela está afastado, o que se compreende principalmente ao verificar a distância temporal entre o presente da enunciaçáo e o relato de acontecimentos passados (...) É por isso que, do ponto de vista do enunciado, o pacto autobiográfico prevê e admite falhas, erros, esquecimentos, omissōes e deformaçōes na história do personagem (...) (p. 76).
É essa metodologia de "escuta da memória" que aparece como prática alternativa na pesquisa em Ensino de Ciências. A aplicação da pesquisa quantitativa à investigação em Ensino de Ciências começou a ser questionada. É uma oposição a métodos quantitativos do positivismo lógico, que são orientados à busca das causas dos fenômenos sociais, sem interesse pela dimensão subjetiva e utilizam procedimentos controlados; são objetivos; orientados à verificaçáo e são hipotético-dedutivos; assumem, assim, uma realidade estática; são orientados aos resultados, são replicáveis e generalizáveis.

Entretanto, há uma crítica feita ao discurso freudiano, que nos traz um alerta para os cuidados que se deve ter com a utilização de biografias. Não há ruptura com o solipsismo do sujeito, pois Freud retira a verdade da CS e coloca no ICS, ou seja, o sujeito continua sendo a origem do conhecimento, numa clara oposição ao objeto. E, em pesquisa, a crítica que se faz é que muitas vezes, ao usar biografias, não conseguimos romper com o discurso singular.

Há um desafio a ser ultrapassado: a construção de conhecimento a partir da relação entre memória individual e memória coletiva, que passa pela necessidade de reconhecer a função política da recuperação da memória. No caso da pesquisa a partir das biografias de professores, é possível produzir "contra-memória" (BUENO et al, 1993), que significa ir além das práticas mais imediatas, pois favorece a desconstrução de esteriótipos sobre o lugar de professor produzidos ao longo da história e mais do que isso, eles deixam de ser "meros recipientes do conhecimento gerado pelos pesquisadores (...) para se tornarem arquitetos de estudos e geradores de conhecimento" (BUENO et al, 1993, p. 307).

No Brasil, com a Abertura Política em meados dos anos 80 e com a produção de um discurso crítico na Educação nos anos 90, a Área de Ensino de Ciências e Matemática vem apresentando aproximaçóes ainda tímidas de uma abordagem histórico-social do processo de aprendizagem.

É possível hoje identificar essa abordagem em Ensino de Ciências, que vem se constituindo a partir da perspectiva histórico-cultural de Vygotsky, que, embasada no discurso marxista, ressalta a importância da interação social no processo de construção do conhecimento. (VYGOTSKY, 2001). Apresenta, assim, um sujeito que de fato é diferente do sujeito cartesiano, pois se constitui em ato, nas relaçôes sociais.

O sujeito não é essência, mas se constitui no discurso, na linguagem, que não é mera expressão do pensamento. Esse é um sujeito histórico, constituído a partir das condiçôes de possibilidade político-econômico-sociais.

Esse discurso nos apresenta uma nova perspectiva de pesquisa na Área de Ensino de Ciências, pois passa-se a analisar o discurso, do ponto de vista do ator social, utilizando a observação naturalista e não controlada; gerando dados subjetivos. Estes são métodos exploratórios, descriti- 
vos e indutivos; são orientados ao processo e assumem uma realidade dinâmica; não sendo generalizáveis. Esta ênfase epistemológica aproxima a área de Ensino de Ciências das concepçôes mais políticas.

Esse novo lugar traz aproximaçóes com áreas que passam pela mesma transformação, como a área de Saúde, para além do modelo biologizante - o homem como fenômeno natural, surge a perspectiva de um conceito de homem que afirme sua constituição a partir do contexto histórico social. A Saúde deixa de ser objeto das práticas tradicionais em hospitais e postos de saúde e ganha outros lugares, um deles a escola.

$\mathrm{Na}$ escola a demanda por um ensino que toque nas questôes de Promoção de Saúde e de Educação para a Saúde são feitas, sobretudo, às ciências naturais (Física, Química e Biologia). No entanto, com a ampliaçáo do conceito de Saúde, esses saberes precisam se aproximar das ciências humanas e sociais, que darão o suporte para as discussôes acerca da interferência das questóes econômicas, políticas e sociais na constituição do processo de saúde. Isso pode permitir à Área de Ensino de Ciências um fortalecimento do sujeito histórico-social na construção do conhecimento científico.

\section{CONCLUSÁO}

A proposta que aproxima Ensino de Ciências, Saúde e Ciências humanas é reveladora de um novo operador ético para além do discurso da Modernidade, ou seja, é preciso estabelecer uma relação entre professor e aluno pautada na valorização do saber do outro; não apenas evidenciando as concepçóes prévias dos alunos, mas, sobretudo, respeitando o contexto histórico-social. Isso significa tomar o ensino de ciências em uma perspectiva libertadora, pois é a busca de que a Ciência possa contribuir para interferir na realidade concreta e essa realidade, como diz Freire (1981), se constitui nas demandas dos diversos grupos sociais.

\section{REFERÊNCIAS}

1. ALBERTI, Verena. Literatura e Autobiografia: A Questão o Sujeito na Narrativa. In: Estudos Históricos, Rio de janeiro, v.4, n. 7, 1991, pp. 66-81.

2. ARRUDA, Sérgio e VILLANI, Alberto. "Mudança Conceitual no Ensino de Ciências". Cadernos Catarinenses de Ensino de Física, v. 11, n. 2, ago./1994, pp. 88-99.

3. BUENO, Belmira Oliveira et al. "Docência, Memória e Gênero: estudos alternativos sobre a formação de professores". In: Psicologia USP, São Paulo, 4(1/2), pp. 299-318, 1993.

4. FREIRE, Paulo. Criando Métodos de Pesquisa Alternativa: aprendendo a fazê-la melhor através da ação. IN: BRANDÃO, Carlos (org.) Pesquisa Participante. São Paulo: Brasiliense, 1981.

5. FREUD, Sigmund (1900). A Interpretação dos Sonhos. In: Obras Completas. Rio de janeiro, Imago, 1987.

6. MOREIRA, Marco Antônio. "Apresentação da REMPEC” Revista Eletrônica do Mestrado Profissional em Ensino de Ciências. V.1, N. 1, abr/2008. www. unipli.com.br/mestrado/rempec. Data e Hora de Acesso: 15/08/09. 14:15h.

7. PIAGET, Jean. Seis Estudos em Psicologia. $13^{\text {a }}$ edição. Rio de Janeiro: Forense-Universitária, 1986.

8. VILLANI, Alberto e CABRAL, Tânia Cristina Baptista. Mudança Conceitual, Subjetividade e Psicanálise. IENCI - Investigaçóes em Ensino de Ciências. Julho, 2001. http://www.if.ufrgs.br/public/ensino/vol2/n1/mudanca.htm. Data e Hora de Acesso: 20/08/09. 16:05h.

9. VYGOTSKY, Liev. Pensamento e Linguagem. 10a edição. Petrópolis: Vozes, 2001.

Endereço para Correspondência:

Luiza Rodrigues de Oliveira - luiza.oliveira@gmail.com Universidade Severino Sombra, NAPE - NÚCLEO AVANÇADO DE PESQUISA E EXTENSĀO - CAMPUS MARICÁ

Av. Governador Roberto Silveira, 437

Flamengo - Maricá - RJ

CEP: 24900-000 